\title{
The ethics of innovation: Columbus and others try something new
}

\author{
Martin F. McKneally, MD, PhD
}

When is it ethically acceptable to embark on an innovation that involves the life and health of human subjects? Our authors regularly submit new operations, devices, and management techniques for publication in the Journal. Because professional journals and organizations are held accountable for their implicit endorsement of off-label and novel practices that prove to be dangerous or harmful, Editor Larry Cohn asked me to comment on the ethics of innovation. I'll begin and end with a case, describe an ethics framework for innovation, and recommend a practical approach that has served us well.

\section{THE CASE}

Christopher Columbus hypothesized that he could develop a shorter trade route to India by sailing straight west across the Atlantic. He was an experienced captain who had exceptional knowledge of ocean currents and celestial navigation. He had sailed as far west as the Canary Islands, $100 \mathrm{~km}$ off the west coast of Africa. During these innovative excursions, he did not fall off the edge of the world or encounter the dragons depicted on maps of that era. The currents off the Canaries, where he was alleged to have kept a mistress, ran westward toward an uncharted new world.

Should Columbus have told the sailors he recruited that he was not planning to follow the navigational convention of sailing down the coast of Africa and around the Cape of Good Hope in constant sight of land? His seasoned colleague Pinchon, the captain of the Niña, advised recruiting seamen with the usual inducements-a good ship, good captain, rum, and the prospect of shared treasure-without mentioning the innovation of sailing an uncharted course. If Columbus insisted on full disclosure, Pinchon recommended recruiting convicted prisoners with the promise of a royal pardon if they survived. Columbus retired to a monastery to seek consultation with the monks, pray for guidance, and make a decision. What should Columbus do?

\section{ETHICS FRAMEWORK}

Ethics is a plural noun. An ethic is a set of values, principles, beliefs, and standards of conduct that guide the behavior of a specified group, such as journalists, lawyers, or

\footnotetext{
From the Department of Surgery and Joint Centre for Bioethics, University of Toronto, Toronto, Ontario, Canada.

Received for publication Dec 14, 2010; revisions received Dec 14, 2010; accepted for publication Jan 3, 2011.

Address for reprints: Martin F. McKneally, MD, PhD, University of Toronto, 77 Forest Grove Dr, Toronto, ON M2K1Z4, Canada (E-mail: martin.mckneally@ utoronto.ca).

J Thorac Cardiovasc Surg 2011;141:863-6

$0022-5223 / \$ 36.00$

Copyright (c) 2011 by The American Association for Thoracic Surgery doi:10.1016/j.jtcvs.2011.01.003
}

doctors. The ethic of surgery, with its foundational values of competence and commitment, is a singularly intense version of the ethic of medicine. The magnitude of the violations of physical integrity and dignitary rights of surgical patients ${ }^{1}$ and the immediacy of the surgeon's personal engagement and responsibility contribute to this singularity.

Surgeons take pains to explain in detail the goals, consequences, and expected outcomes of the surgical interventions they plan to perform. The variability of the terrain in which we practice leads to inevitable unplanned innovation: "We couldn't remove the tumor, but we were able to bypass it," or "We had only one donor lung, so we did a contralateral volume reduction on the recipient to maximize function." ${ }^{2}$ Such innovations are morally justified in the court of professional opinion by their reasonableness, the lack of better alternatives, and their congruence with the values and principles of the surgical community.

Planned innovations, like Columbus' voyage, require definition and forethought. Innovation is a notional concept. There are many notions of its meaning, and no widely accepted definition. To distinguish innovation from the minor incremental changes that surgeons introduce in the course of everyday practice, we have defined surgical innovation as "a new evolving intervention whose effects, sideeffects, safety, reliability and complications are not widely known." "3 This definition is intended to encompass transformative rather than incremental changes. Although the boundary between minor incremental improvements and major transformative innovations is difficult to define, it is easy to recognize. McBurney's decision to remove the appendix through a small, muscle-splitting incision transformed the treatment of appendicitis. Prestigious advocates of traditional management, including William Osler, were adamantly opposed to his approach. McBurney thought that the conventional treatment-hot packs to the abdomen, morphine analgesia, turpentine enemas, rectal insufflation of tobacco smoke, and eventual drainage of the periappendicial abscess-was inadequate. Against the prevailing beliefs of medical and surgical colleagues, he developed a bold new transformative treatment.

The guidance documents on the ethics of innovation are reasonable but insufficient. For example, the Declaration of Helsinki ${ }^{4}$ is the Journal's reference standard; it authorizes us to try unproven treatments when nothing else works, to save life, re-establish health, or alleviate suffering. "In the treatment of a patient, where proven interventions do not exist or have been ineffective, the physician, after seeking expert advice, with informed consent from the patient or a legally authorized representative, may use an unproven intervention if in the physician's judgment it 
offers hope of saving life, re-establishing health or alleviating suffering. Where possible, this intervention should be made the object of research designed to evaluate its safety and efficacy. In all cases, new information should be recorded and, where appropriate, made publicly available." The problem with this principle is that it allows innovation only where proven interventions do not exist or are ineffective. Innovations in areas that might make the treatment cheaper, quicker, less debilitating, or easier to teach are ignored. We innovate to improve interventions that are already in existence and effective but may be too expensive, slow, uncomfortable, or inconvenient.

A thoughtful book, Ethical Guidelines for Innovative Surgery, ${ }^{5}$ summarizing 5 years of study and 2 conferences on surgical innovation, addresses some of these issues. It will reward careful reading and provides a basis for further research.

\section{ETHICAL ISSUES SPECIFIC TO INNOVATIVE SURGERY}

An issue is an important social question to which there is often more than one reasonable answer. The important issues confronting innovators and those accountable for innovations are consent, validity, competence, conflict of interest, cost, and oversight.

\section{Consent}

The issue of consent is particularly sensitive and easily mismanaged. In a progressive society, procedures that are described as new are often presumed to be improvements relative to those that are older. Patients subjected to unproven interventions should be explicitly informed about the innovation's novelty and lack of a proven record of effectiveness. Consent for the first patient to undergo heart surgery with cross-circulation is well described in G. Wayne Miller's excellent book King of Hearts: The True Story of the Maverick Who Pioneered Open Heart Surgery. ${ }^{6}$ "The Gliddens remembered their daughter LaDonnah, who had been born with the same [ventricular septal] defect.... They were willing to try almost anything to spare their baby Gregory their daughter's fate." ${ }^{\prime 6}$ In obtaining their consent for a landmark innovative operation, "[Walt] Lillehei told the Gliddens that his "artificial heart" was actually another person-in fact, one of them. [He] drew a diagram of cross-circulation and talked of his experimental success with dogs. ${ }^{, 6}$ In contrast, many innovators are tempted to take the easy and less transparent approach, saying simply, "We have a new [and, by implication, better] way to do your operation." Participants undergoing innovative interventions should be informed of the novelty of the undertaking.

\section{Validity}

The issue of validity is less settled with innovation than with accepted standard procedures, although many of the latter remain unvalidated. Valid interventions are effective, well-founded, and able to produce the desired result. The word valid derives from the Latin validus, meaning strong. An innovation may be presumed to be valid if it is founded on reasonable evidence of feasibility and effectiveness. This evidence may come from unplanned successful experience in an emergency, studies in animals, or demonstrations in the anatomy or pathology laboratory. Further support may come from the experience and endorsement of peers working with similar frontier technologies and techniques. Introduction of an innovation is ethically justified on the grounds of probable validity, as judged by competent professionals. This remains a claim until validating evidence has been developed with the help of well-informed, willing patients. Successful application in their care provides the basis for eventual recognition of the innovation as a validated component of the surgical armamentarium.

\section{Competence}

A foundational element of the surgical ethic is competence to perform the appropriate surgical intervention with a high probability of success and a low risk of complications. Many innovations challenge the competence of the surgical team. The learning curve-the progression in knowledge and skill in performance of innovative procedures - should be managed collaboratively with colleagues under professional oversight. ${ }^{7}$ There is an additional issue of the impact on training. As teachers work on mastering new techniques, such as robotic cardiac surgery or video-assisted thoracic surgery, the operative experience of their residents and fellows is inhibited. In some instances, gaining sufficient confidence to teach new procedures can take a year or longer.

\section{Conflicts of Interest}

Conflicts of interest arise in "situation(s) in which an interest (financial, personal, political) can interfere with a duty." 8 The financial, personal, or reputational interests of innovative surgeons can compete with their fiduciary duty to put patients' interests first. The temptation to increase market share, academic credit, or personal notoriety may lead to overuse or less attention to the cost of new technology. Professional oversight can help to manage this risk.

\section{Cost}

The issue of cost arises because innovations in health care have been linked to the rapid rise in the cost of health care, potentially disadvantaging such other priorities as education and highway safety. Technologic innovation is believed to be responsible for the rise of the cost of health care at 2 to 3 times the rate of inflation. At hospitals emphasizing frontier technologies, the rate may be substantially higher. This conflict is an issue in societal justice, not simply a hospital management problem. 


\section{Oversight}

The issue of oversight requires special consideration. Responsibility for ensuring that consent, validity, conflicts of interest, and cost are managed correctly is a professional issue. The chief of service and the institutional trustees are held publicly accountable when innovations go awry. Although some institutions delegate responsibility for oversight to institutional [ethics] review boards or research ethics boards, innovation is not research. There is a family resemblance between them, arising from their experimental nature.

Research is designed to produce generalizable knowledge, with carefully controlled methods for patient selection and treatment assignment and with specified uniform techniques and outcome measures. The conduct of research is specified in predetermined, agreed, approved protocols to minimize the effects of chance variables. In contrast, the methods, patient selection, technical steps, and management are constantly evolving during the development of an innovative surgical procedure (Table 1). The innovators' question is, "How can we make this work?" With time, patient selection, management approaches, instrument modifications, and techniques evolve. When all these have been settled, formal research can be undertaken to test hypotheses about the innovation, to answer the question, "Is this better than the standard approach?".

Almost every major advance in medicine and surgery has been introduced through the pathway of innovation. Anesthesia, antibiotics, arthroscopy, aneurysmectomy, and aortic valve replacement exemplify only a few of the $a$ 's. Innovations can be hypothesis generating, but formal research to compare the outcomes with conventional treatment follows relatively rarely.

\section{THE CASE REVISITED}

Columbus did disclose his novel plan to the men he recruited. Unlike Pinchon, he reasoned that they should not all be thought of as identical members of a single category, with identical attitudes toward risk. This wise decision gave more risk-averse candidates, or those with pregnant wives or aging parents, the opportunity to opt out of a heroic adventure with unknown risks.

Rejection of Pinchon's prisoner proposal may have saved Columbus's life. When the voyage stretched longer and lon-

TABLE 1. Innovation versus research

\begin{tabular}{lll}
\hline & Innovation & \multicolumn{1}{c}{ Research } \\
\hline Techniques & Evolving & Defined \\
Outcome measures & Evolving & Defined \\
Patient selection & Evolving & Defined \\
Conclusions & Tentative, & Generalizable \\
& particular & \\
Oversight & Professional & Societal (institutional \\
& & review board, research \\
& & ethics board) \\
\hline
\end{tabular}

ger and the crew became restless, some turned against the captain, considering mutiny. If he had chosen criminals, with their ingrained distrust of authority and advanced education in violence, he might not have lived to celebrate his discovery of Hispaniola and the new world.

\section{HOW WE INTRODUCE SURGICAL INTERVENTIONS}

At several of the teaching hospitals at the University of Toronto, a helpful "Enabling Innovation" protocol has been in place for several years. ${ }^{9}$

1. The surgeon initiates an "Enabling Innovation Letter" to the Surgeon-In-Chief (SIC), describing the innovative procedure or device, the rationale for the request (including expected benefits, risks, and costs), and the names of 2 informed colleagues who endorse the validity of the proposal. These may be internal or external advisors whom the SIC can consult if needed.

2. The surgeon pledges to add the "Columbus Clause" to the standard consent form: "I understand that this treatment is new to this hospital. I will be one of the first $[\mathrm{x}]$ patients to receive it here. I have been offered the standard treatment. My doctors and nurses are working to find the best way to perform the new treatment and learn which patients will benefit most from it."

3. If needed, the SIC consults members of an unconvened innovation task force of nursing, anesthesia, engineering, ethics, and legal personnel who are familiar with the Enabling Innovation pathway.

4. The SIC shows the letter and consent form to the chair of the research ethics board, who accepts or advises full review. This step proved useful in the early adoption phase of the policy. The research ethics boards no longer consider this necessary unless the SIC decides it is appropriate.

5. The innovator reports the outcomes of the first patients treated to the SIC, with help from hospital data managers and cost estimates from the operating room manager.

6. Formal research is initiated if and when appropriate.

Like Columbus' sailors, patients are not identical members of a single category with identical attitudes toward risk. Some are intensely risk averse, some are foolishly adventurous, and some are heroes who are well suited to participate in advancing the frontier of medical science. Because the risks and outcomes of innovative surgical procedures are not always predictable, it seems fair and responsible to use more thorough procedures for disclosing the uncertainties associated with innovative surgical interventions.

In summary, surgical innovations should be able to meet ethical standards of appropriate consent (including disclosure of their novelty), validity, competence, management of the conflicts of interest that might encourage their overuse, assessment of the impact of their cost on institutional or 
societal resources, and oversight to ensure that the consent, validity, conflict of interest, and cost criteria are managed correctly.

Bryce Taylor, Jacob Langer, John Wedge, and Randi ZlotnikShaul contributed to the development of the Enabling Innovation policy. Deborah McKneally made helpful revisions to the manuscript.

\section{References}

1. McKneally MF. Managing expectations and fear: invited commentary on "Indecency in cardiac surgery: a memoir of my education at a super-esteemed medical place (SEMP)," by Dr. Edmund Erde. J Card Surg. 2007;22:49-50.

2. Todd TR, Perron J, Winton TL, Keshavjee SH. Simultaneous single-lung transplantation and lung volume reduction. Ann Thorac Surg. 1997;63:1468-70.
3. McKneally MF, Daar A. Introducing new technologies: protecting subjects of surgical innovation and research. World J Surg. 2003;27:930-5.

4. World Medical Association. WMA declaration of Helsinki ethical principles for medical research involving human subjects [Internet]. Ferney-Voltaire, France; 2008. Available at: http://www.wma.net/en/30publications/10policies/b3/index. html. Accessed January 30, 2011.

5. Reitsma AM, Moreno JD. Ethical guidelines for innovative surgery. Hagerstown, MD: University Publishing Group; 2006.

6. Miller GW. King of Hearts: the true story of the maverick who pioneered open heart surgery. New York, NY: Random House; 2000:4-6, 107.

7. McKneally MF. Video-assisted thoracic surgery: standards and guidelines. Chest Surg Clin North Am. 1993;3:345-51.

8. Khushf G, Gifford R. Understanding, assessing, and managing conflicts of interest. In: McCullough LB, Jones JW, Brody BA, eds. Surgical ethics. New York, NY: Oxford University Press; 1998:342-66.

9. McKneally MF. Editor's column: enabling innovation. Univ Toronto Surg Spotlight [Internet]. Winter 2005-2006:15. Available at: http://www.surgicalspotlight.ca/ Shared/PDF/Winter06.pdf. Accessed January 30, 2011. 